\title{
Administração pública comparada: uma avaliação das reformas administrativas do Brasil, EUA e União Européia*
}

\author{
José Matias-Pereira**
}

Sumário: 1. Introdução; 2 . As bases teóricas do surgimento e desenvolvimento do Estado-providência; 3. As molas impulsoras da nova administração pública; 4. Os distintos modelos de reformas sociais da Europa; 5. Avaliando as reformas da gestão pública: uma perspectiva internacional; 6 . Formas de operacionalização das reformas; 7. O sistema de previdência social nos EUA; 8. As motivações da reforma da administração pública em Portugal; 9. Experiência de redução da informalidade na Espanha; 10. Avanços e distorções na administração pública do Brasil; 11. Conclusões.

Summary: 1 . Introduction; 2 . Theoretical framework of the emergence and development of the providential state; 3 . The driving force of the new public administration; 4. The different social reform models in Europe; 5 . Assessing the public management reforms: an international perspective; 6 . Ways for implementing the reforms; 7 . US Social security system; 8 . The motivation for the public administration reform in Portugal; 9. The reduction of informality experience in Spain; 10. Advances and distortions of the public administration in Brazil; 11. Conclusions.

Palavras-chave: administração pública; reforma administrativa; modelos comparados (EUA, União Européia e Brasil).

KEY WORDs: public administration; administrative reform; compared models (USA, European Union, and Brazil).

Este artigo aprofunda o debate, no âmbito da ciência da administração pública — sob o enfoque da administração pública comparada —, sobre a evolução e os problemas

\footnotetext{
* Artigo recebido em nov. 2005 e aceito em set. 2006.

** Professor e pesquisador do programa de Pós-Graduação em Administração da Universidade de Brasília. Pós-doutor em administração pela Faculdade de Economia, Administração e Contabilidade da Universidade de São Paulo (FEA/USP). Doutor em ciência política — área de governo e administração pública - pela Faculdade de Ciências Políticas e Sociologia da Universidade Complutense de Madri, Espanha. Endereço: Campus da UnB, ICC Norte, Subsolo, Programa de Pós-Graduação em Administração Campus da UnB, Asa Norte - CEP 70910-970, Brasília, DF, Brasil. E-mail: matias@unb.br.
} 
recentes na gestão da administração pública no Brasil, EUA e União Européia. A análise revela que as reformas administrativas chegaram à maioria dos países do mundo impelidas pelo Consenso de Washington. Distintos estudos constatam que, a new public management (NPM — nova gestão pública) pode ter afetado muitos países, mas o teria feito em alguns de forma mais profunda. Observa-se que, tanto no Brasil quanto nos países selecionados, fortes elementos de continuidade podem ser identificados, depois de mais de 20 anos de reforma, demonstrando que as reformas colaboraram muito pouco em termos de estabilidade ou satisfação.

Comparative public administration: an assessment of the administrative reforms in Brazil, USA and the European Union

This article deepens the discussion, within the public administration science and from the comparative public administration perspective, about the recent evolution and problems in the management of the public administration in Brazil, USA and the European Union. The analysis reveals that administrative reforms have arrived to most countries impelled by the Washington Consensus. Distinct studies evidence that the New Public Management (NPM) may have affected many countries, but it had a deeper effect in some than in others. Both in Brazil and in the selected countries in this article strong elements of continuity can be identified after over 20 years of reform, showing that the reforms have helped very little in terms of stability or satisfaction.

\section{Introdução}

A existência de uma profunda diversidade cultural, regimes políticos diferentes e formações históricas específicas que existem de país para país imprime em cada um deles uma feição única, o que explica as variações sobre os objetivos, estilos administrativos, funções e papel da administração pública no mundo. Observa-se que na administração empresarial busca-se de forma incessante modelos considerados universalmente válidos, enquanto no estudo da administração pública ocorre, em geral, uma perspectiva comparada. Desde o parlamentarismo ao presidencialismo, dos modelos de funcionários de confiança aos modelos de burocracia plena e permanente, culturas e sociedades diferentes propiciam opções e estratégias institucionais diferenciadas de organização política e de ação pública.

As reformas administrativas chegaram à maioria dos países do mundo impelidas pelo Consenso de Washington. Nessa orientação, em especial para os países em desenvolvimento latino-americanos, o Banco Mundial, em 1997, já ressaltava a importância das capacidades burocráticas para o desenvolvimento. A implantação dessas reformas foi realizada por etapas. Para a teoria da path-dependent (dependência de caminhos), os processos passados tendem a influenciar o presente. Assim, instituições herdadas condicionam fortemente os 
caminhos a serem tomados, determinando, inclusive, a persistência de arranjos institucionais pouco eficientes.

O neo-institucionalismo, por sua vez, na busca de entender a cooperação voluntária, afirma a importância das instituições para o funcionamento da economia, visto que as imperfeições do mercado requerem o estabelecimento de regras que organizem a ação coletiva. Para North (1991), as instituições são definidas como regras, formais ou informais, idealizadas pelos homens para criar ordem ou reduzir a incerteza nas trocas. Assim, instituições e organizações - respectivamente, as regras do jogo e a divisão de tarefas entre os agentes que participam - afetam o desempenho da economia à medida que, ao dar forma e estruturar as interações humanas, reduzem as incertezas e induzem a cooperação, diminuindo os custos das transações.

Tendo esse quadro como pano de fundo, aprofundamos neste artigo o debate, no âmbito da ciência da administração pública, sob o enfoque da administração pública comparada, a evolução e problemas recentes na gestão da administração pública no Brasil, EUA e União Européia.

\section{As bases teóricas do surgimento e desenvolvimento do Estado-providência}

O surgimento do Estado do bem-estar está relacionado a três elementos essenciais: a existência de excedentes econômicos passíveis de serem realocados pelo Estado para atender às necessidades sociais; o pensamento keynesiano, que estruturou a sua base teórica; e a experiência de centralização governamental durante a II Guerra Mundial, que fomentou o crescimento da capacidade administrativa do Estado. Apoiado nesses elementos básicos foram desenvolvidas distintas teorias para explicar o surgimento e o desenvolvimento do Estado de bem-estar social. Destacam-se, entre elas, além da teoria neo-institucional, a teoria da convergência ou lógica da industrialização; a teoria da cidadania; e, a teoria marxista.

A partir dessas considerações, torna-se possível avançar, a seguir, nos aspectos essenciais das reformas administrativas implementadas no mundo contemporâneo, que chegaram à maioria dos países do mundo, especialmente nos países em desenvolvimento, impelidas pelo Consenso de Washington. Nessa orientação se ressaltava a importância das capacidades burocráticas para o desenvolvimento. Deve-se ressaltar que, sua implantação se realizou por etapas.

A pergunta inicial neste artigo é: quais foram os resultados das reformas gerenciais no Brasil, nos EUA e na União Européia, partindo de uma perspectiva comparada? 
Este artigo é qualitativo e essencialmente bibliográfico. Possui diversas limitações. A principal é decorrente da amplitude e complexidade dos problemas que nele são abordados e debatidos. Apesar disso, esperamos que as reflexões e observações feitas encorajem a realização de outras discussões e avaliações úteis, que não foram aqui tratadas.

A middle-range theory é o principal referencial teórico deste artigo, entendida aqui como a "nova administração pública". Registre-se que a middle-range theory busca encontrar respostas para enfrentar as questões decorrentes das profundas mudanças que afetam a administração no mundo contemporâneo. Entre os autores que cuidam do tema administração pública comparada destacamos os trabalhos de Dwivedi e Henderson (1990); Khator e Garcia-Zamor (1994); Guess (1998); Welch e Wong (1998); Pollitt e Bouckaert (2000); e Brans (2003).

\section{As molas impulsoras da nova administração pública}

Observa-se, tendo como divisor a década de 1980, que o mundo caminhou de uma administração pública comparada clássica ou tradicional para uma nova administração pública. Esta última, apoiada na denominada middle-range theory foi estimulada pela necessidade de encontrar respostas para problemas como: eficiência, eficácia, efetividade, legitimidade democrática, impacto das tecnologias da informação na administração, entre outros e por avanços em uma série de disciplinas ligadas à teoria organizacional, ciência política e economia (neo-institucionalismo e public choice). A partir dessas novas idéias procurou-se abandonar a generalização e aproveitar o grande número de informação publicada sobre a administração pública dos mais diferentes países no mundo.

A administração pública comparada deve ser entendida aqui como o domínio do saber que compara padrões de administração pública entre diferentes Estados-nação. Nesse sentido, busca estudar as semelhanças e diferenças entre várias unidades de análise, nos níveis da organização, da gestão e da política (no sentido dado ao termo anglo-saxônico policy), com o propósito de se criar uma base de conhecimento institucionalizado que possa auxiliar a tomada de decisão (Guess, 1998:535; Heredia e Schneider, 2003).

Observa-se que os teóricos da administração pública, no passado, se preocupavam em focar os seus estudos nos fenômenos administrativos dentro do seu próprio país, no quadro do seu sistema político-administrativo específico. Esse contexto foi profundamente alterado com a globalização, que trouxe no seu bojo uma maior discussão dos problemas administrativos e das soluções encontradas, bem como uma ampla difusão dos estudos sobre o tema, em es- 
pecial, os relatórios e trabalhos elaborados pela OCDE, FMI, BIRD, American Society for Public Administration e European Group for Public Administration. A globalização fomentou as mudanças na teoria e na prática da administração pública, abandonando as tendências paroquiais que têm permeado a ciência da administração nos diferentes países (Khator e Garcia-Zamor, 1994:10).

Para alguns autores, como por exemplo, Caiden (1994:45), essa tendência a olhar para outras realidades traz ainda vantagens científicas já que, ao se adotar uma perspectiva comparativa e global, evita-se o erro de tecer generalizações apenas com base no estudo de uma realidade administrativa restrita (a administração pública dos EUA, por exemplo). Registre-se que existe uma tendência de que os problemas que muitos países possuem são comuns aos demais, para os quais também se poderão encontrar soluções semelhantes. Assim, despesa pública elevada na economia, baixo nível de eficiência, eficácia e efetividade na administração pública, o crescente nível de insatisfação dos cidadãos com a qualidade dos serviços prestados pela administração pública, são problemas inerentes a quase todos os países. Nesse sentido, a utilização do método comparativo nos estudos que visam à resolução desses problemas poderá ser bastante útil na busca de resolver esses problemas comuns.

\section{Os distintos modelos de reformas sociais da Europa}

O "modelo europeu" vem sofrendo significativos impactos provocados pelos reflexos das mudanças implementadas na administração pública da Grã-Bretanha, nos últimos 25 anos. A constatação de que o liberalismo anglo-saxão, supostamente selvagem, está atropelando a civilizada economia européia é bastante perceptível para uma boa parte dos estudiosos do tema.

Observa-se que os efeitos provocados pela economia moderna na Europa são distintos do que ocorreu nos EUA. Se nos EUA os efeitos benéficos provocados pelos imigrantes entusiasmados são evidentes, na Europa conviveu-se com camponeses desconfiados. Após uma sucessão de catástrofes, os europeus conseguiram alcançar um adequado equilíbrio entre esforço individual e responsabilidade coletiva depois da II Guerra Mundial. Todos os europeus ocidentais compartilham um compromisso em relação ao que é, em comparação com padrões mundiais, um generoso Estado de bem-estar social.

Essas constatações não significam, por sua vez, que a Europa tenha um único modelo de reformas sociais. Ao contrário, é perceptível que a Europa convive com distintos modelos de reformas sociais. Sapir (2005), ao tratar desse tema, ressalta que: 
1. O "modelo nórdico" (Dinamarca, Finlândia, Suécia e Holanda) tem os mais elevados gastos públicos aplicados em proteção social e provisão de bem-estar universal. Os mercados de trabalho são relativamente desregulamentados, mas existem políticas "ativas" visando ao mercado de trabalho, enquanto sindicatos fortes proporcionam um grau elevado de igualdade salarial.

2. O modelo "anglo-saxão" (Irlanda e Reino Unido) proporciona uma assistência social de última instância bastante generosa, com transferências de dinheiro destinadas principalmente a pessoas em idade economicamente ativa. Os sindicatos são frágeis e o mercado de trabalho é relativamente desregulamentado. 3. O "modelo renano" (Áustria, Bélgica, França, Alemanha e Luxemburgo) baseia-se em seguro social para os desempregados e na provisão de aposentadorias. A proteção ao emprego é mais forte do que nos países nórdicos. Os sindicatos também são poderosos ou desfrutam de apoio legal para a extensão de resultados de negociação coletiva.

4. O "modelo mediterrâneo" (Grécia, Itália, Portugal e Espanha) concentra gastos públicos no pagamento de aposentadoria de idosos. Forte regulamentação protege (e diminui) o emprego, ao passo que generoso apoio a aposentadorias antecipadas busca reduzir o número de pessoas em busca de trabalho.

Essas distinções não são absolutas, mas a tipologia é reveladora. Os países europeus adotam níveis elevados de proteção ao emprego (no modelo mediterrâneo), e uma elevada cobertura de seguro-desemprego (nos modelos anglo-saxão e nórdico), sendo o modelo renano um meio-termo. Em termos comparativos, verificamos que a posição dos EUA é totalmente diferenciada em relação a essas questões.

Numa avaliação preliminar, Sapir (2005) afirma que essas diferentes políticas funcionam adequadamente na consecução de dois objetivos europeus fundamentais: elevados níveis de emprego e eliminação da pobreza relativa. Observa-se que, em relação ao primeiro objetivo, o modelo nórdico e o anglo-saxão podem ser bem avaliados. O desempenho dos modelos renano e mediterrâneo apresenta um funcionamento precário. Quanto ao segundo objetivo, os modelos renano e nórdico têm bom desempenho e os mediterrâneo e anglo-saxão funcionam de forma insatisfatória. Para Sapir a principal razão para o desempenho insatisfatório do modelo anglo-saxão na redução da pobreza não é a insuficiência de redistribuição fiscal, mas padrões educacionais insatisfatórios na base.

O modelo nórdico é bom tanto para o emprego como para reduzir a pobreza, e o modelo mediterrâneo é mau. Por outro lado, o modelo anglo-saxão é bom para o emprego e mau para a redução da pobreza, ao passo que com o modelo renano ocorre o contrário. Os modelos anglo-saxão e nórdico são eficientes (pelo menos para o mercado de trabalho), ao passo que os modelos renano e nórdico são igualitários. 
Os modelos ineficientes podem também ser insustentáveis. Nesse sentido, argumenta o autor que os países renanos e mediterrâneos têm proporções mais elevadas de dívida pública em relação ao PIB, de 73\% e 81\%, respectivamente, contra 36\% no grupo anglo-saxão e 49\% entre os nórdicos.

Registre-se que a importância dos países renanos e mediterrâneos é muito grande: eles geram dois terços do PIB de toda a União Européia (UE) ampliada e $90 \%$ do PIB, em comparação com a zona do euro. Para Sapir, eles deveriam tornar-se ou mais nórdicos ou mais anglo-saxões. A essência da mudança estaria na eliminação da proteção explícita ao emprego. Proteção rigorosa do emprego é particularmente inadequada em um período de rápidas mudanças econômicas, quando velhas funções e práticas tradicionais já não predominam. É melhor promover a empregabilidade do que proteger o emprego e, simultaneamente, proporcionar seguro contra o impacto de curto prazo do desemprego.

Por sua vez, não existem dúvidas sobre o êxito dos países nórdicos. Mas todos esses países (relativamente pequenos) têm populações com alto nível de escolaridade e um comprometimento compartilhado com níveis excepcionalmente elevados de bem-estar social provido pelo Estado. Na Dinamarca, Finlândia e Suécia, a proporção de gastos públicos em relação ao PIB é superior a $50 \%$.

Assim, em primeiro lugar, é perceptível que o modelo pode ser relevante para a Alemanha ou para a França, mas sua aplicabilidade aos países mediterrâneos é discutível. Em segundo lugar, o objetivo (implícito) dos modelos de bem-estar social renano e mediterrâneo é proteger os empregos e rendas dos chefes de família. O modelo anglo-saxão não alcança tal objetivo devido a desigualdades de renda bastante maiores. As evidências indicam, em terceiro lugar, que a UE é, em larga medida, irrelevante quanto a essas decisões, porque a estrutura dos Estados de bem-estar social e as regulamentações dos mercados de trabalho continuam, em maioria esmagadora, nas esferas nacionais.

Conclui-se, dessa forma, que a Europa tem modelos de política econômica que parecem funcionar toleravelmente bem e oferecem algo bastante distinto de "capitalismo selvagem". Isso é significativamente verdadeiro para o modelo nórdico. A questão é em que medida outros países europeus podem adotar quaisquer das alternativas aparentemente superiores. Uma questão parece evidente, simplesmente opor resistência a mudanças é — dos pontos de vista econômicos e político - uma atitude inadequada. Pode ser difícil para os europeus aprenderem uns com os outros. Deixar de fazê-lo poderá revelar-se ainda mais doloroso (Sapir, 2005). 


\section{Avaliando as reformas da gestão pública: uma perspectiva internacional}

Para Pollitt e Bouckaert (2000), a tarefa de avaliar as reformas da gestão pública numa perspectiva internacional é um exercício científico difícil e problemático. Para os autores cinco problemas parecem emergir: a unidade de análise para uma comparação internacional é menos óbvia do que parece. Níveis de governo são diferentes de setores e de instrumentos e processos específicos. A unidade de sentido é o segundo problema, pois pode ser que uma agência não seja uma agência. A ausência e a qualidade dos dados, além das séries temporais constituem outro conjunto de problemas. A multiplicidade de critérios para se definir a reforma e a imponderabilidade da mudança é um outro problema metodológico. Por fim, desenham um quadro rústico e classificam os esforços de reforma em termos de quatro estratégias principais (quatro $\mathrm{Ms}$ ): manter, modernizar, "mercadificar" e minimizar.

Pollitt e Bouckaert (2001) argumentam que a intenção de avaliar as reformas de gestão em todo o mundo é, por várias razões, uma tarefa quase impossível. Para eles é compreensível que ela tenha sido tentada, por tão poucas vezes, e geralmente por pessoas, como políticos, consultores em gestão e gurus, que se sentem livres das inibições científicas da academia. Argumentam que a simples frase "comparações internacionais" parece pressupor que Estados nacionais sejam a unidade de análise mais apropriada para uma avaliação das reformas de gestão pública.

No estudo que fizeram sobre 10 países, Pollitt e Bouckaert (2000) encontraram fortes evidências das diferenças nacionais. Constatam que a new public management (NPM) pode ter afetado muitos países, mas alguns teriam sido afetados de forma mais profunda. Observa-se que mesmo aqueles países que estão bastante influenciados por ela tendem a adaptá-la de forma quase individual, para produzir receitas nacionais diversas. Essas diferenças são preocupantes, pois países distintos têm diferentes pontos de partida, com histórias diversas, e seguem trajetórias distintas.

Uma maneira de classificar os esforços de reforma é pensar em termos das quatro principais estratégias que qualquer um pode usar. Elas são:

v manter - conservar a máquina administrativa tal como ela é, mas ajustar e equilibrar sempre que possível;

- modernizar - realizar as mudanças mais fundamentais nas estruturas e processos, por exemplo, mudando a orientação do processo orçamentário de insumo para produto; criando novos tipos de organização do setor público, como agências autônomas; modificando o contrato de trabalho dos servidores públicos etc.; 
$\checkmark$ mercantilizar - introduzir mecanismos de mercado (market-type mechanis$m s$ - MTMs) no setor público, acreditando que eles vão gerar eficiência e melhor desempenho (OCDE, 1993);

v minimizar - reduzir o setor estatal tanto quanto possível, fazendo o máximo uso da privatização e da contratação externa. Os ativos públicos são vendidos, e as atividades anteriormente desempenhadas por servidores públicos são oferecidas aos setores comerciais e voluntários.

\section{Formas de operacionalização das reformas}

Na Grã-Bretanha os governos conservadores dos anos 1990 introduziram um "mercado interno" para o Serviço Nacional de Saúde, de modo que os hospitais tivessem que competir pelos pacientes em termos de preço e qualidade dos serviços. Dessa forma, as atividades continuam dentro do setor estatal, mas as organizações estatais são obrigadas a se comportar cada vez mais como empresas do setor privado. Essa estratégia reflete a atitude pessimista com relação ao potencial do setor público para a boa gestão e a legitimidade da propriedade estatal.

Em termos gerais, os países "anglo-saxões" (Austrália, Estados Unidos, Nova Zelândia e Reino Unido) foram além desses parâmetros e de forma mais rápida pelos dois últimos caminhos (mercantilizar e minimizar) do que a maioria dos países da Europa continental.

Verifica-se que ambas as estratégias tendem a criar maior resistência por parte das organizações do setor público e sindicatos. A mercantilização e a minimização são mais radicais e mais conflituosas do que a manutenção e a modernização. Os ganhos possíveis são divulgados - por seus proponentes - como maiores, mas os riscos de fracasso e de resistência são significativamente altos. Os países da Europa continental preferiram um impulso central rumo à modernização, temperado com uma pitada ocasional de mercantilização e privatização.

\section{As reformas não-estruturais do modelo de proteção social europeu}

O modelo europeu de proteção social (Solorio, 1998), baseado em princípios pregados pela Organização Internacional do Trabalho (OIT) e pela Associação Internacional de Seguridade Social (AISS), preconiza as reformas não-estruturais que operam principalmente dentro dos sistemas gerais de seguridade social dos países da Organização para Cooperação e Desenvolvimento Econômico (OCDE). 
Essas reformas não-estruturais baseiam-se em sete características principais:

v redução das prestações gerais ou específicas, como forma de compatibilizar os custos crescentes com redução da relação de dependência. Em geral, atingem as aposentadorias de mais altos valores;

v modificação na fórmula para o cálculo das prestações, geralmente aumentando os anos necessários para a aposentadoria;

aumento da idade de aposentadoria, em combinação com aposentadoria parcial, antecipada;

- reajuste das prestações pelo índice do custo de vida ou outros índices;

v aumento das alíquotas de contribuição, geralmente de um modo progressivo;

v igualdade de tratamento entre homens e mulheres;

v aumento dos regimes complementares nos sistemas de seguridade social.

As reformas, em geral, são implantadas progressivamente, em médio ou no longo prazo (por exemplo, na Alemanha, o processo está previsto até 2030), ou de modo consensual, com um pacto entre diversos setores sociais (por exemplo, na Espanha, o Pacto de Toledo). O esforço que vem sendo desenvolvido é para manter o sistema de bem-estar social estabelecido na Europa desde o final da II Guerra Mundial. A certeza é que terá que ser reformado pelas condições impostas pela globalização e pelas tendências demográficas.

\section{Avaliação da previdência social na União Européia}

As projeções indicam que os países da Europa (UE), em 2030, contarão com 20 milhões de pessoas a menos na sua força de trabalho. Os cálculos atuariais mostram que o sistema previdenciário, mantida essa tendência, não poderá suportar os gastos decorrentes dessas mudanças demográficas. Para as autoridades da União Européia não existe alternativa: trabalhar até mais tarde, ou redução no valor das aposentadorias. Será preciso, ainda, gerar estímulos para aumentar a natalidade.

A Holanda, Áustria e Dinamarca reformaram seus sistemas de previdência, com corte de alguns benefícios, mas mantiveram os direitos fundamentais e têm na atualidade taxas baixas de desemprego e déficit. Entre os 15 paísesmembros mais antigos da UE, os gastos médios variam de $25 \%$ a $30 \%$ do PIB com benefícios sociais. A preocupação é com a qualidade do gasto. 
Tabela 1

Perfil da população da União Européia - maiores de 60 anos (países selecionados, 2002)

\begin{tabular}{|lc|}
\hline País & \% da população total \\
\hline Itália & 24,9 \\
Áustria & 21,5 \\
Alemanha & 24,2 \\
França & 20,6 \\
Holanda & 18,4 \\
\hline
\end{tabular}

Tabela 2

$\%$ de aposentados e pensionistas na população total (países selecionados, 2002)

\begin{tabular}{|lc|}
\hline País & Aposentados e pensionistas \\
\hline Itália & 28,4 \\
Alemanha & 27,5 \\
\hline Fonte: Eurostat Yearbook, 2005.
\end{tabular}

Tabela 3

Gastos com benefícios previdenciários

(União Européia e países selecionados, 2002)

\begin{tabular}{|lc|}
\hline País & $\%$ PIB \\
\hline Itália & 14,9 \\
Áustria & 14,6 \\
Alemanha & 13,4 \\
Holanda & 13,1 \\
UE 15 & 12,6 \\
\hline
\end{tabular}

Fonte: Eurostat Yearbook, 2005.

Tabela 4

Participação das pensões/aposentadorias nos gastos totais com benefícios sociais (União Européia e países selecionados, 2002)

\begin{tabular}{|lc|}
\hline País & Participação \% \\
\hline Itália & 59,5 \\
Áustria & 51,6 \\
Alemanha & 45,7 \\
França & 45,3 \\
Holanda & 48,9 \\
UE 15 & 47,1 \\
\hline
\end{tabular}


Tabela 5

Déficit público (União Européia e países selecionados, 2002)

\begin{tabular}{|lc|}
\hline País & $\%$ PIB \\
\hline Itália & 3,2 \\
Áustria & 1,0 \\
Alemanha & 3,7 \\
França & 3,6 \\
Holanda & 2,1 \\
UE 15 & 2,6 \\
\hline
\end{tabular}

Fonte: Eurostat Yearbook, 2005.

\section{0 sistema de previdência social nos EUA}

Nos EUA a "previdência social" é apenas um pilar do sistema de aposentadoria de "três pilares", os outros dois são as previdências fornecidas pelas empresas e as poupanças privadas. A utilização do termo "previdência social" na maioria dos países latino-americanos - bem como nos países europeus - tem uma conotação de assistência médica. Muitos sistemas de aposentadoria fora dos EUA oferecem seguro-saúde nacional, pensões por invalidez e seguro-desemprego.

O trabalhador, nos EUA, aplica o seu dinheiro em um plano de previdência, a empresa patrocinadora para qual ele trabalha costuma desenvolver o plano e depois lhe dizer quais são suas opções de investimento. Nesse sentido, os empregadores americanos assumem uma enorme responsabilidade ao traçar os planos. É sabido que um sistema previdenciário bem estruturado deve ofertar contas de baixo custo diversificadas e indexadas, além de uma administração pouco dispendiosa. É a melhor proteção para o participante. A questão nos EUA, em especial recentemente, tem sido como se proteger contra os denominados "canalhas" do mercado.

\section{As motivações da reforma da administração pública em Portugal}

Portugal é um dos países da União Européia que aplica mais recursos na sua administração pública, sem que sejam visíveis, em termos de eficiência e eficácia, os resultados correspondentes. Apoiado nessa constatação é que o governo português está propondo reformas na administração pública do país. A elaboração de um diagnóstico recente foi o ponto de partida para a reforma que tem de ser feita. Ele condensa o conjunto das grandes orientações que presidirão a reforma da administração pública em Portugal. 
A reforma visa prestigiar a missão da administração pública e os seus agentes, na busca da exigência e da excelência; delimitar as funções que o Estado deve assumir diretamente, com vantagem para o cidadão; promover a modernização dos organismos, qualificando e estimulando os funcionários, inovando processos e introduzindo novas práticas de gestão; introduzir uma nova idéia de avaliação dos desempenhos, seja dos serviços, seja dos funcionários; apostar na formação e na valorização dos funcionários públicos. Em síntese, o que se pretende é uma administração ao serviço do cidadão, uma administração amiga da economia, uma administração motivadora de todos quantos nela trabalham.

\section{Portugal 2010: acelerar o crescimento da produtividade em Portugal}

O objetivo do estudo "Portugal 2010" foi identificar as principais barreiras à produtividade com base em uma análise aprofundada de nove setores selecionados. A principal barreira identificada é a da informalidade, descrita como o não-cumprimento das obrigações por parte dos agentes econômicos. Ela representa perto de $28 \%$ do diferencial global de produtividade identificado como "atacável", produzindo impactos muito significativos não apenas ao nível de setores não-transacionáveis como a construção civil, mas também em setores transacionáveis como a indústria automobilística.

A informalidade deve ser entendida como o conjunto de distorções ao enquadramento competitivo e empresarial da economia resultantes da evasão por parte de empresas e agentes econômicos a um conjunto de obrigações. Não se trata apenas da existência de fenômenos de "economia paralela", mas de um conjunto mais amplo de comportamentos freqüentemente verificados, como os seguintes:

v evasão fiscal, principalmente a impostos sobre o rendimento das empresas e particulares (IRC e IRS) e ao imposto sobre o valor adicionado (IVA);

v evasão a obrigações sociais, como o não-cumprimento dos pagamentos devidos à Segurança Social ou o não-pagamento de níveis de salário mínimo;

- evasão a normas de mercado, designadamente o não-cumprimento de exigências de níveis mínimos de qualidade dos produtos, de normas de segurança, de restrições ambientais, de direitos de propriedade etc.

Esta barreira tem impactos profundos na economia, muito para além dos habitualmente discutidos nas receitas do Estado e da Segurança Social: 
v trabalho retido em atividades pouco produtivas. Agentes econômicos menos eficientes detêm uma presença de mercado (quota de mercado) superior à que obteriam se não se beneficiassem das vantagens de preço e margem permitidas pela evasão fiscal e às obrigações sociais. Por exemplo, no setor do varejo alimentar, os varejistas informais beneficiam-se de seis pontos percentuais (cerca de 50\% da margem) suplementares em termos de rentabilidade das vendas face aos seus concorrentes formais;

v maior produtividade do trabalho, resultando da distorção no custo relativo dos fatores (tornando-se o fator trabalho mais barato pela evasão às normas laborais e aos compromissos de Segurança Social);

v distanciamento das melhores práticas domésticas e internacionais por receio ou incapacidade de convivência dos agentes econômicos internacionais com as práticas de informalidade e com a falta de transparência vigente no mercado. Por exemplo, no setor da construção civil, os players internacionais detêm uma quota de mercado residual, representando menos de $3 \%$ do total do mercado;

- dificuldade em estabelecer as condições e dimensões necessárias à inovação e disseminação de melhores práticas, uma vez que os agentes informais evitam o crescimento ou relacionamentos profundos com parceiros ou financiadores, como forma de mais facilmente evitarem o escrutínio externo de práticas de informalidade.

\section{Experiência de redução da informalidade na Espanha}

$\mathrm{Na}$ Espanha os níveis de informalidade eram significativamente elevados na década de 1990. O governo espanhol desenvolveu um intenso programa de redução da informalidade nas pequenas e médias empresas. Dessa forma conseguiu aumentar de $75 \%$ a $100 \%$ a arrecadação dos tributos dessas pequenas e médias empresas.

A criação do programa integrado espanhol de combate à informalidade teve como base o seguinte conjunto de iniciativas:

v racionalização do sistema fiscal, mediante simplificação do Código Fiscal, facilitando a sua implementação e reduzindo os custos do seu cumprimento;

v reforço dos mecanismos de auditoria (fiscal, segurança social, laboral etc.), assegurando a integração das fontes de informação, e automatizando os processos de verificação e referenciação cruzada de dados;

- aplicação de penalidades acrescidas (monetárias e não-monetárias) nos casos de evasão; 
- reforço da conscientização da opinião pública e empresarial para a importância do cumprimento;

v redesenho organizativo da administração pública, com vista a uma maior especialização e integração das atividades de fiscalização e prevenção, particularmente em setores com maior peso de informalidade.

\section{Avanços e distorções na administração pública do Brasil}

O processo de modernização da administração pública no Brasil, entre as décadas de 1930 e 1990, seguiu alguns padrões, entre eles a fragmentação institucional e a separação entre a formulação e a implementação política. A retórica da reforma dos anos 1990 avançou do ponto de vista da utilização do conceito de governança e dos princípios políticos que orientaram as propostas, quais sejam: participação, accountability, controle social.

Apesar de ter ocorrido a transposição de técnicas de gestão do setor privado para o setor público, a agenda mostrou-se bastante restrita, uma vez que a lógica do processo decisório, que inclui formulação e implementação, não foi objeto da reflexão política. A forma como a reforma foi idealizada e conduzida mostrou-se falha, em especial pela insuficiência de mecanismos de coordenação política. Isso contribuiu para manter a fragmentação de ações no campo da gestão pública.

A reforma do Estado brasileiro deflagrada em 1995 teve como objetivo — tendo parte integrante a reforma administrativa - manter equilibradas as contas públicas e, ao mesmo tempo, elevar a capacidade da ação estatal. A reforma propõe uma reconfiguração das estruturas estatais baseada na substituição do modelo burocrático de administração pública por um modelo gerencial.

Por tratar-se de um modelo pós-burocrático, buscou importar ferramentas de gestão provenientes do setor privado, bem como a aplicação da lógica de mercado dentro do setor público, focalizando o aumento da eficiência econômica do Estado. Em harmonia com as experiências internacionais que estavam em curso, inicia-se, assim, um amplo processo de revisão das formas de prestação dos serviços públicos no Brasil.

A reforma gerencial no Brasil, inspirada no gerencialismo britânico, também recebeu influência dos princípios da new public management (NPM). Assim, o Plano Diretor de Reforma do Aparelho do Estado, coordenado pelo Ministério da Administração e Reforma do Estado (Brasil, 1995), fortemente apoiado na new public management e na progressive governance, incorporou muitos elementos do paradigma neodesenvolvimentista. A implantação da NPM no Brasil procurou delinear um novo padrão de gestão pública, a denominada 
"administração gerencial", apoiada nos princípios da flexibilidade, ênfase em resultados, foco no cliente e controle social.

Observa-se que no processo de transformação institucional no setor público brasileiro, orientado nos últimos 15 anos, prevalece a visão do paradigma neoliberal, tendo como referência a preocupação com o "ajuste fiscal". A face pouco visível dessas recomendações é a geração de estímulos para promover o desmantelamento do Estado brasileiro. Esse quadro evidencia, de forma preocupante, as enormes dificuldades para encontrar novas alternativas e corrigir disfunções de um Estado de direito inacabado. Esse Estado de direito, sobre o qual se erigiram nossas instituições republicanas, federativas e democráticas, apresenta enormes imperfeições estruturais, especialmente nos âmbitos da Justiça, das instituições políticas, da forma e regime de governo, e em especial no campo social, onde não tem sido capaz de reduzir as desigualdades e promover a inclusão social.

O efetivo exercício do poder no Brasil depende da capacidade do Poder Executivo de propor e implementar uma agenda de governo. No Brasil a paralisia do Executivo - diferente do que ocorre no parlamentarismo tipicamente europeu, no âmbito do qual a integração Executivo-Parlamento é patente; e diferentemente do presidencialismo norte-americano, onde o Legislativo compete com o Executivo na formulação e supervisão da implementação das políticas públicas - conduz ao vácuo ou à predação política.

Na gestão pública, o país nunca chegou a ter um modelo de burocracia pública consolidada. Constata-se a existência de um padrão híbrido de burocracia patrimonial. Há uma trajetória de construção burocrática e outra de construção democrática, mas ambas parecem reciprocamente disfuncionais (Martins, 1997). É perceptível que o Estado patrimonialista está fortemente presente na cultura política brasileira e se manifesta no clientelismo, no corporativismo, no fisiologismo e na corrupção.

A crise da burocracia pública brasileira permeia as dimensões da estratégia (foco e convergência de programas e ações), da estrutura (lenta, excessiva em alguns setores, escassa em outros), dos processos (sujeitos às regras padronizadas altamente burocratizadas), das pessoas (com inúmeras distorções relativas à distribuição, carência, qualificação e remuneração), dos recursos (inadequados, desde os logísticos e instalações à tecnologia da informação, embora haja focos de excelência) e da cultura (excessivamente burocrática e permeável às práticas patrimonialistas).

\section{O processo de formulação e implementação de políticas públicas}

A capacidade da administração pública de realizar e obter resultados em benefício da sociedade depende, em geral, do modo como se encontra estru- 
turada. É sabido que a organização é o ponto de partida para o sucesso da administração pública. Nesse esforço de se organizar está implícita a necessidade de definir com clareza a dimensão, o papel e as funções do Estado. Um Estado com dimensões excessivas e que interfere em todas as áreas tende a não cumprir adequadamente as suas funções. Nesse contexto, um Estado moderno é aquele que tem a capacidade de distinguir as funções essenciais que somente cabe ao Estado executar, das funções acessórias, que podem ser exercidas por outras entidades, sob a supervisão do Estado, bem como as funções inúteis que, como tal, não faz sentido nem têm razão de ser executadas (Matias-Pereira, 2003).

$\mathrm{Na}$ análise de políticas de gestão pública é essencial levar em consideração o exame do processo de formulação e de implementação de políticas. Os aspectos que envolvem a fragmentação e a formação de consensos para reformas da gestão pública tendem a conduzir à preocupação com a racionalidade que permeia o processo de formulação e de implementação de políticas.

Os temas que integram a agenda da gestão como, por exemplo, recursos humanos, logística, planejamento e orçamento, são entendidos como de domínios técnicos especializados. Essa especialização, por sua vez, vem sendo reproduzida na definição de funções e na estrutura organizacional que apóia o processo de decisão política nesse campo. É sabido que a especialização do conhecimento não é obstáculo a uma ação articulada de diversos atores individuais, portadores de conhecimentos especializados. Uma enorme rede de atores e de organizações integra os esforços de implementação do processo de políticas. Isso é salutar no âmbito da gestão pública, visto que a definição de problemas e as aplicações de soluções resultam de uma ação coletiva. À medida que aumenta o número de atores, maior será a complexidade do processo político e o desafio de coordenação das ações.

Observa-se que o tema "reforma da administração pública no Brasil" tem estado presente, especialmente após 1995, nos debates e na agenda política do país. Essas reformas, que deixaram muito a desejar, retomam com maior intensidade na primeira década do século XXI, visto que uma nova sociedade e uma nova economia exigem uma administração pública mais competitiva, eficiente e transparente.

Tendo como base de apoio uma estrutura pesada, burocrática e centralizada, a administração pública brasileira não tem sido capaz de responder, como organização, às demandas e aos desafios da modernidade. As evidências disponíveis sinalizam como resultado dessas deficiências e distorções:

v uma reconhecida incapacidade de satisfazer, de forma eficaz e tempestiva, as necessidades dos cidadãos; 
v uma forma de funcionamento que prejudica a concorrência e a competitividade internacional do país e das empresas;

v falta de coerência do modelo de organização global;

$\checkmark$ processos de decisão demasiado longos e complexos, que impedem a resolução, em tempo útil, dos problemas dos cidadãos e que criam desconfiança em matéria de transparência e de legalidade;

v falta de motivação dos funcionários e desvalorização do próprio conceito de missão de serviço público.

\section{Choque de gestão na administração pública: diagnóstico}

É perceptível, na atualidade, que a intenção do governo federal de implementar um novo processo de planejamento, com participação social, não conseguiu atingir os seus propósitos de estimular a modernização da administração pública. Na medida em que essa modernização não se efetivou, e na tentativa de retirar o governo da inércia instalada no governo federal - em grande parte provocada por inúmeras denúncias de corrupção - , destaca-se a proposta de realizar um choque de gestão na administração pública.

Por sua vez, observa-se que o governo federal encontra-se num dilema, diante de suas próprias contradições e ineficiências. Tomar decisões corretas, principalmente sobre assuntos técnicos, exige uma administração pública profissional. Os sinais de que isso não ocorre na atualidade está evidenciado em: debates estéreis, criação sistemática de grupos de trabalho, conselhos e disputas políticas localizadas, que são divulgados pela mídia diuturnamente. Evidencia-se que a decisão do governo de nomear seletivamente os dirigentes sindicalistas e os membros do Partido dos Trabalhadores para ocupar a maioria dos cargos de direção na máquina pública do Estado - com 34 ministérios, 189 órgãos da administração indireta, 11 agências e 11 bancos, e 1,8 milhão de servidores civis e militares —, sem levar em consideração a competência técnica, foi uma decisão política equivocada. É sabido que qualquer governo, para atender adequadamente às demandas da sociedade, necessita contar com uma administração pública profissional. Com a politização da administração pública direta e indireta brasileira verifica-se que o desempenho governamental foi prejudicado.

As avaliações recentes sobre o desempenho da administração pública no Brasil indicam que o ponto de estrangulamento do governo federal encontra-se no campo operacional, visto que a administração pública para obter sucesso nas suas políticas públicas depende da competência de seus funcionários. Programas e projetos com deficiências de "gestão" tendem a dificultar o alcance dos objetivos 
das políticas públicas, além de propiciar a geração de corrupção. Um choque de gestão na administração pública deve ter como propósito a modernização do Estado, para torná-lo menos burocrático e mais competitivo. Por meio da eficiência na administração dos recursos públicos, buscará o governo solucionar um maior número de demandas da sociedade, que devem estar traduzidas nas suas políticas públicas contidas no orçamento da União.

Assim, o propósito do governo federal de realizar um "choque de gestão" em curto prazo não é uma medida factível. A complexidade e extensão de ações que serão necessárias para viabilizar um projeto dessa envergadura, que necessita ser discutido intensamente com a sociedade organizada, somente irão produzir resultados em médio e longo prazos. Um choque de gestão no Brasil exige que sejam reexaminadas as distorções provocadas pelos custos de uma carga tributária próxima de $40 \%$ do PIB — nos três níveis de governo: federal, estados e municípios - , com baixo retorno dessa arrecadação para a sociedade. Exige, também, que sejam adotadas medidas para reduzir as dificuldades na vida dos cidadãos, com imposições burocráticas perversas e injustificadas.

A demora de quase seis meses para a abertura de uma empresa ou a cobrança de 61 diferentes espécies de tributos - fatores que prejudicam o funcionamento da economia - evidenciam que o Estado brasileiro não está contribuindo de forma adequada para estimular o país a avançar rumo à modernidade econômica. É irreal imaginar que um "choque de gestão", apoiado apenas na imposição de seletividade nos gastos públicos e na definição de metas fiscais - como o aumento do superávit primário para 4,75\% do PIB nos próximos três anos -, será suficiente para viabilizar um programa de estabilização e crescimento. Não se pode ignorar que a busca de um Estado moderno e inteligente, menos burocrático e que incentive a competitividade, passa pela continuidade da reforma do Estado, redução drástica da burocracia e realização de reformas estruturais nos campos: tributário, previdenciário, judiciário e político, entre outros. Essa é uma tarefa permanente, que perpassa vários governos.

\section{Conclusões}

Este artigo buscou responder a questão: quais foram os resultados das reformas gerenciais no Brasil, nos EUA e na União Européia, partindo de uma perspectiva comparada? Existem evidências de que o modelo de reforma administrativa implementado nos países selecionados neste artigo, sob a ótica neoliberal, não se mostrou capaz de resolver adequadamente os problemas da administração pública.

A experiência da reforma administrativa que vem sendo implementada na Grã-Bretanha mostra que a reforma naquele país não tem fim. Apesar da intensa reforma gerencial realizada nas duas últimas décadas, os resultados não podem 
ser aceitos como satisfatórios. Isso fica explícito nas declarações do governo trabalhista de Tony Blair, que tem sinalizado que é necessário mensurar mais, desenhar melhor as metas, mais avaliação, mais tecnologia da informação, mais mudança cultural para o servidor público (White Paper). Por sua vez, as inúmeras reformas administrativas implementadas na França evidenciam que houve mudanças, mas os elementos de continuidade, como a centralização dos grands corps e seu tipo particular de profissionalização tecnocrata, ou a força política dos sindicatos do serviço público, continuam presentes. A mudança negociada, seja incremental ou gradual, tem sido a norma na Alemanha, nos Países Baixos e nos Estados nórdicos.

Existem indícios de que a NPM, na prática, tenha sido prejudicada pelo amadorismo dos seus proponentes no seu próprio campo de desempenho. Em teoria, a NPM está totalmente ligada à melhoria do desempenho — fazer os governos mais conscientes em relação a custos, eficientes, eficazes, compreensivos, voltados à satisfação do cliente, flexíveis e transparentes. Na prática, porém, os esforços orientados para mensurar se realmente houve melhoria no desempenho ficaram muito abaixo do esperado. Isso pode ser constatado no caso britânico, onde o governo não realizou diversas avaliações no conjunto de reformas orientadas por desempenho.

Uma avaliação, sob um prisma mais amplo, evidencia que houve mudança estrutural e uma evolução cultural nos países que deram mais impulso às idéias da NPM - Austrália, Nova Zelândia e Reino Unido. Mesmo neles, fortes elementos de continuidade podem ser identificados, depois de mais de 20 anos de reforma, demonstrando que colaboraram muito pouco em termos de estabilidade ou satisfação. A especulação sobre a existência de uma nova cultura ainda não está comprovada.

No que se refere ao Brasil, podemos argumentar que o modelo de reforma do Estado - dual e linear —, implementado sob a ótica neoliberal, não se mostrou capaz de resolver adequadamente os problemas socioeconômicos do país. Ficou evidenciado que, em geral, além da ausência de vontade política dos governantes, as reformas - apoiadas em decisões pontuais e casuísticas - se apresentaram desarticuladas e incoerentes. Os custos dessas distorções se refletem na capacidade de competitividade do país, na vida dos cidadãos e na motivação dos funcionários públicos.

\section{Referências bibliográficas}

BRASIL. Ministério da Administrção e Reforma do Estado. Plano Diretor da Reforma do Aparelho de Estado. Brasília, 1995.

BRANS, M. Comparative public administration: from general theory to general frameworks. In: PETERS, B. G.; PIERRE, J. (Eds.). Handbook of public administration. London: Sage Publications, 2003. 
CAIDEN, G. E. Globalizing the theory and practice of public administration. In: GARCIA-ZAMOR, J-C.; KATHOR, R. (Eds.). Public administration in the global village. London: Praeger, 1994.

; CAIDEN, N. Towards the future of comparative public administration. In: DWIVEDI, O. P.; HENDERSON, K. M. (Eds.). Public administration in world perspective. Ames: Iowa State Press, 1990.

DAHL, R. The science of public administration: three problems. In: STIVERS, C. (Ed.). Democracy, bureaucracy, and the study of administration. Oxford: Westview Press, 2001.

DWIVEDI, O. P.; HENDERSON, K. M. State of the art: comparative public administration and development administration. In: . (Eds.). Public administration in world perspective. Ames: Iowa State Press, 1990.

EUROSTAT YEARBOOK 2005. Luxembourg: Office for Official Publications of the European Communities, 2005. Disponível em: <htpp://epp.eurostat.ec.europa.eu/ portal/page?_pageid $=1073,46587259 \&$ _dad $=$ portal\&_schema $=$ PORTAL\&p_product_code $=$ KD-CD-05-001 > . Acesso em: fev. 2008.

GUESS, G. M. Comparative and international administration. In: RABIN, J.; HILDRETH, W. B.; MILLER, G. J. (Eds.). Handbook of public administration. 2. ed. New York: Marcel Dekker, 1998.

HEADY, F. Introduction. In: DWIVEDI, O. P; HENDERSON, K. M. (Eds.). Public administration in world perspective. Ames: Iowa State Press, 1990.

Issues in comparative and international administration. In: RABIN, J.; HILDRETH, W. B.; MILLER, G. J. (Eds.). Handbook of public administration. 2. ed. New York: Marcel Dekker, 1998.

. Public administration: a comparative perspective. 6. ed. New York: Marcel Dekker, 2001.

HEREDIA, B.; SCHNEIDER, R. B. (Eds.). Reinventing Leviathan. The politics of administrative reform in developing countries. Miami: North South Center Press, 2003.

KHATOR, R.; GARCIA-ZAMOR, J. C. Introduction. In: . (Eds.). Public administration in the global village. London: Praeger, 1994.

NORTH, D. Institutions, institutional change and economic performance. Cambridge: Cambridge University Press, 1991. p. 3-26.

MARTINS, H. F. A ética do patrinionialismo e a modernização da administração pública brasileira. In: MOTTA, F. C. P.; CALDAS, M. P. (Orgs.). Cultura organizacional e cultura brasileira. São Paulo: Atlas, 1997. 
MATIAS-PEREIRA, J. Reforma do Estado e controle da corrupção no Brasil. Revista de Administração Mackenzie, v. 4, n. 1, p. 39-58, 2003.

OCDE. The Frascati manual. 5. ed. Paris: OCDE, 1993.

PIERRE, J. Comparative public administration: the state of the art. In: (Ed.). Bureaucracy in the modern state: an introduction to comparative public administration. Aldershot: Edward Elgar, 1995.

POLLIT, C., BOUCKAERT, G. Public management reform: a comparative analysis. Oxford: Oxford University Press, 2000.

. Avaliando reformas da gestão pública: uma perspectiva internacional. In: AVALIANDO A NOVA GESTÃO PÚBLICA NO MUNDO, 2001. Anais... Rio de Janeiro, 13 e 14 set. 2001.

PORTUGAL. Portugal 2010: acelerar o crescimento da produtividade. Síntese de conclusões. McKinsey \& Company e McKinsey Global Institute (MGI). Lisboa: Ministério da Economia de Portugal, set. 2003.

SAPIR, A. Globalization and the reform of European social models. Sept. 2005. Disponível em: <www.bruegel.org >. Acesso em: 10 nov. 2005.

SOLORIO, C. Los regimenes de pensiones, su evolución y características de reforma. Países seleccionados de la OCDE. Depto. Seg. Soc. de OIT, set. 1998.

WELCH, E.; WONG, W. Public administration in a global context: bridging the gaps of theory and practice between Western and Non-Western nations. Public Administration Review, v. 58, n. 1, p. 40-49, 1998. 